\title{
Colloidal Behavior of Aqueous Montmorillonite Suspensions in the Presence of Non-ionic Polymer
}

\author{
Mourad Gareche ${ }^{1}$, Nadjet Azril ${ }^{1}$, Leila Saoudi ${ }^{1}$, Jean Charles Dupin ${ }^{2}$, Ahmed Allal $^{2}$ and Noureddine Zeraibi ${ }^{1}$ \\ 1. LGPH, Department of Oil Field, University M'hamed Bougara of Boumerdes, 35000, Algeria
}

2. IPREM-EPCP, Helioparc, University of Pau and Contries of Adour, 64053, France

\begin{abstract}
In this paper, we characterized at first, the rheological behavior of the bentonite suspensions and the aqueous solutions of PEO (polyethylene oxide). Then we are going to investigate the influence of this polymer in a water-based drilling fluid model (6\% of bentonite suspension). The objective is to exhibit how the non-ionic polymer with molecular weight $6 \times 10^{3} \mathrm{~g} / \mathrm{mol}$. of varying concentration mass $(0.7 \%, 1 \%, 2 \%$ and $3 \%)$ significantly alter the rheological properties (yield stress, viscosity, loss and elastic modulus) of the bentonite suspensions. The rheological measurements made in simple shear and in dynamic on the mixture (water-bentonite-PEO), showed rheological properties of bentonite suspensions both in the presence and absence of non-ionic polymer. The PEO presents an affinity for the bentonite particles slowing down their kinetic aggregation. The analysis by XRD (X-rays diffraction) also allowed understanding the structure of this mixture. It had revealed the intercalation between of the clay platelets on one hand, and the links bridges assured by the chains of polymer between bentonite particles beyond a critical concentration in PEO on the other hand.
\end{abstract}

Key words: Bentonite, PEO, suspension, rheology.

\section{Introduction}

Clay minerals are extensively used in a wide range of applications. They are key component in the formulation of ceramic products, cement, drilling fluids, moulding sands, paints and paper, among others [1]. An important characteristic that clay minerals are able to provide in such applications is adequate particle dispersion, which is necessary to obtain a uniform and stable system. Under certain conditions the clay particles may become aggregated, which leads to the variation of important properties required for a particular function. In drilling fluids, for example, the flow behavior of the system is of utmost importance due to its circulation a round the wellbore [2]. The aggregation of the clay particles under varying conditions of temperature and electrolytes leads to strong variations of the flow properties. It becomes necessary therefore to add certain additives,

Corresponding author: Mourad Gareche, Ph.D., main research field: rheology and fluid flow. E-mail: gareche.m@gmail.com. or polymers, to stabilise the clay particles and prevent this behavior. In soil science, non-ionic polymers that are water soluble have been found to impart stability to natural soil aggregates. On contact with the particle these molecules tend to collapse and spread out over the clay surface, improving the physical conditions of soil [3]. Since non-ionic polymers appear to be well suited for stabilising a clay structure, there lies fundamental interest to comprehend the structure and flow behavior of the clay / non-ionic polymer systems. In the literature, we find numerous works treating the ternary system water-clay-additive, where the additive is often a non-ionic polymer. By being interested in the interactions particles additives and to understand the microstructure, the authors often couple rheological measures with physico-chemical techniques such as XRD, DLS/SLS (dynamic and static light scattering), TEM (transmission electronic microscope) etc. [4-11].

The purpose of this article is to highlight the rheological properties of bentonite suspensions both in 
the presence and absence of non-ionic polymers, the PEO. The stability of the suspension was enhanced with increasing polymer adsorption. The influence of this additive was investigated in terms of viscosity, yield stress, loss and elastic modulus which are principal characteristics of the drilling fluids.

\section{Experimental}

\subsection{Materials}

In our work, we used the calcic bentonite (B3378) supplied by Sigma-Adrich. Its average composition is (\% mass): $\quad \mathrm{SiO}_{2}-48.35, \quad \mathrm{Al}_{2} \mathrm{O}_{3}-12.15, \quad \mathrm{Fe}_{2} \mathrm{O}_{3}-8.26$, CaO-6.68, MgO-5.47, $\mathrm{Na}_{2} \mathrm{O}-3.65, \quad \mathrm{~K}_{2} \mathrm{O}-2.39$. It possesses a specific surface of $39.3 \mathrm{~m}^{2} / \mathrm{g}$, a capacity cationic exchange of $0.88 \mathrm{meq} / \mathrm{g}, \mathrm{pH}=9$ and a specific gravity of $2.4 \mathrm{~g} / \mathrm{cm}^{3}$.

The PEO supplied by Acros organics, is non-ionic polymer of the polyether's family. Its chemical formula: $\mathrm{HO}-\mathrm{CH}_{2}-\left(\mathrm{CH}_{2}-\mathrm{O}-\mathrm{CH}_{2}-\right) \mathrm{n}-\mathrm{CH}_{2}-\mathrm{OH}$. It possesses a molecular weight $6.10^{3} \mathrm{~g} / \mathrm{mol}$, a number monomer/chain 136, a volumic mass $1173 \mathrm{~kg} / \mathrm{m}^{3}$ and radius gyration $30 \AA$. It was added to the clay suspensions.

\subsection{Samples Preparation}

The bentonite suspensions having mass concentrations of 2, 4, 5, 6 and $8 \%$ were prepared by pouring a volume of clay into demineralised water under a magnetic glass-rod during 24 hours. We noticed, after formulation of suspensions, at a more or less long rest, that is particles sedimentation for $2 \%$ and consistency gel formation with increases concentration another suspension. The same protocol is used to preparation for aqueous solutions PEO (1-5\%).

For the preparation of mixtures (water-bentonite-PEO), the experimental protocol is the following: in the quantity of demineralised water, we add the bentonite. After 6 hours of agitation, the PEO of molecular mass $6 \times 10^{3} \mathrm{~g} / \mathrm{mol}$ is introduced into the basic bentonite suspension (6\%). The homogenization is obtained by magnetic a glass-rod during 48 hours. Before making the rheological measures, every sample is mixed during 45 minutes. After sample's placed in geometry, it's subjected to a preshear, then, we proceed to the measure.

The type of experiment consists in determining the flow curves in simple shear and to study the viscoelatic properties of the different suspensions. The measurements were made with a geometry of coaxial cylinders ( $\Phi 32 \mathrm{~mm} / \Phi 29,5 \mathrm{~mm}$ and $\mathrm{L}: 44,3 \mathrm{~mm})$ for rheometer SR-5000, cone plan $\left(\Phi 60 \mathrm{~mm} / 2^{\circ}\right)$ for Bohlin C-VOR-150. By being interested in interaction particles-additives, we coupled with the rheological measurements, the analysis by XRD realized on Inel XRG-3000.

\section{Results and Discussion}

\subsection{Rheological Measurements of Bentonite} Suspensions

The results available on such suspensions are often very divergent. This can be explained by the diverse qualities of bentonite used (origin, manufacturing, etc.), as well as the practiced experimental methods. Fig. 1 presents the flow curves for the bentonite suspensions of varying concentrations. An increase is noticed in the apparent $\mu$ viscosity and the yield stress which becomes more significant with the increase of concentration. The rheological behavior of these

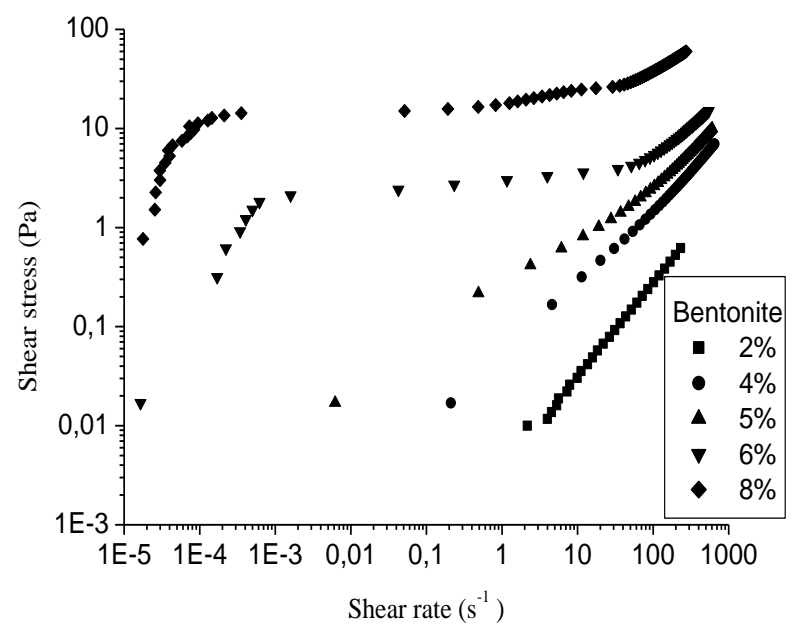

Fig. 1 Flow curves for bentonite suspensions at different concentrations. 
suspensions is thus Newtonian for the concentration value of $2 \%$ and shear-thinning with yield stress beyond this latter.

The increase of the viscosity can explain by the crystalline structure of the mineral group to which belongs the montmorillonite. In the water, the particles of bentonite which have a strong affinity for the environment in which they are scattered, form suspensions possessing a structure in house of cards [12]. They are constituted by minerals the shape of which is generally flattened. These materials are silicates of aluminum the crystalline composition of which is a pile of leaves. The phenomenon of inflation, which is translated by a modification of the rheological characteristics of the suspension, occurs by the penetration of the water between the leaves which provokes their space [13].

The existence of yield stress of flow is associated with the Van der Waals forces, which facilitate the formation of flocs or particles aggregates which provoke a resistance to the flow [14]. It is only significant at relatively concentration beyond $2 \%$ of bentonite. Similar results were obtained by [2] on sodic montmorillonite above $3 \%$ and by [15] on mass fractions from it bentonite beyond value of $2 \%$.

When the shear stress is lower than the "yield stress", the bentonite suspension has the behavior of solid type. There is no flow. But, when the shear stress is sufficient to maintain a flow, the shear rate abruptly increases. The material quickly fluidifies. During this phase, the aggregates of particles were practically destroyed and particles were directed according to current lines.

\subsection{Rheological Measurements of Aqueous Solutions PEO}

The development and the environmental protection, make that the water soluble polymers take an important place to restrict the use of the organic solvents. The PEO associated with particles of clay in an aqueous solution allows to obtain solutions with very interesting rheological properties such as the stabilization of the colloidal suspensions in the drilling fluids. The Fig. 2 presents the flow curves of the PEO solutions for varying mass concentrations $(1 \%, 2 \%$, $3 \%, 4 \%$ and $5 \%$ ). We notice an increase of the viscosity according to the concentration. The behavior of the PEO solutions is quasi-Newtonian.

\subsection{Rheological Measurements of Mixtures} Suspensions Bentonite-PEO

To exhibit, the influence of the PEO on the rheological properties of bentonite suspensions, we have selected a basic suspension of concentration 6\%, into which we introduced the PEO of molecular weight $6 \times 10^{3} \mathrm{~g} / \mathrm{mol}$. by varying its concentration $(0.7 \%, 1 \%, 2 \%$ and $3 \%)$.

\subsubsection{Shear Stress-Shear Rate Measurements}

A shear stress $(\tau)$ - shear rate $(\gamma)$ sweep was applied to each suspension by varying the shear stress over a wide range between 0,017 and $16 \mathrm{~Pa}$. The flow curves were analyzed and fitted to the Herschel-Bulkley model, which has previously been used to describe the flow behavior of clay suspensions applied to drilling fluids [16]. The Herschel-Bulkley equation is given by:

$$
\tau=\tau_{\mathrm{c}}+\mathrm{K} \gamma^{\mathrm{n}}
$$

where $\tau_{c}$ is yield shear stress, $\mathrm{K}$ is the consistency, $\mathrm{n}$ is the flow behavior index and $\mu_{\mathrm{HB}}$ is the high shear viscosity Herschel-Bulkley.

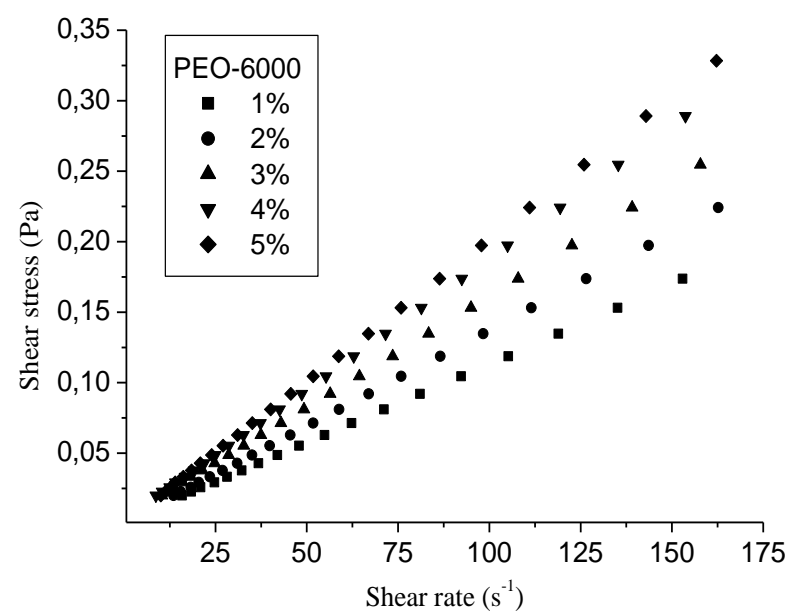

Fig. 2 Flow curves for aqueous solutions PEO at different concentrations. 
The rheological behavior of the bentonite suspension, in the presence of the polymer (PEO) to different concentrations is practically shear-thinning with yield stress (Fig. 3).

However, the PEO provokes, the decrease of the yield stress of the mixture, even the disappearance of this last one for high concentrations of PEO $\left(\tau_{c}\right.$ is determined by the intersection point for the first slope with the second slope of the deformation curve on the $\mathrm{X}$-axis in Fig. 4).

The addition of the PEO in the bentonite suspension allows the progressive covering of the bentonite

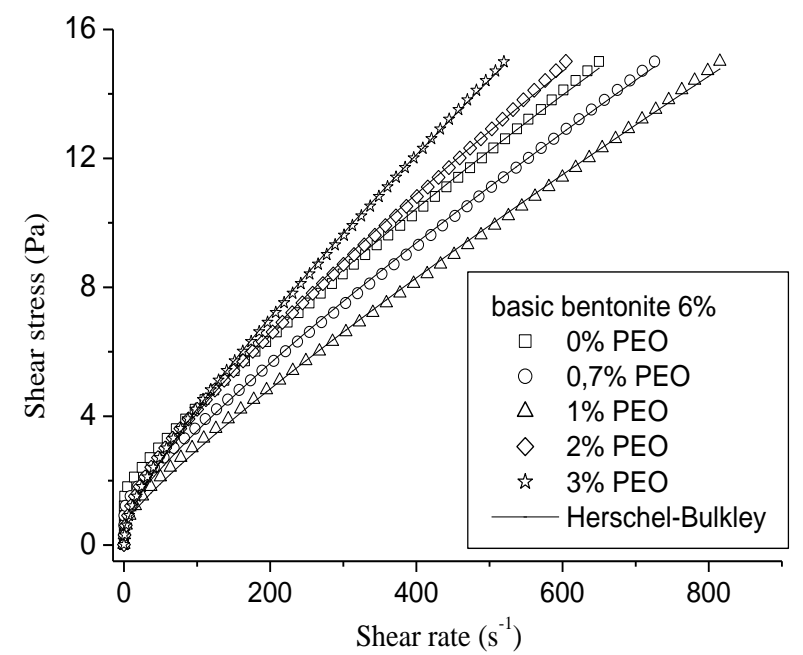

Fig. 3 Modelling of flow curves for mixture bentonite-PEO at different concentrations.

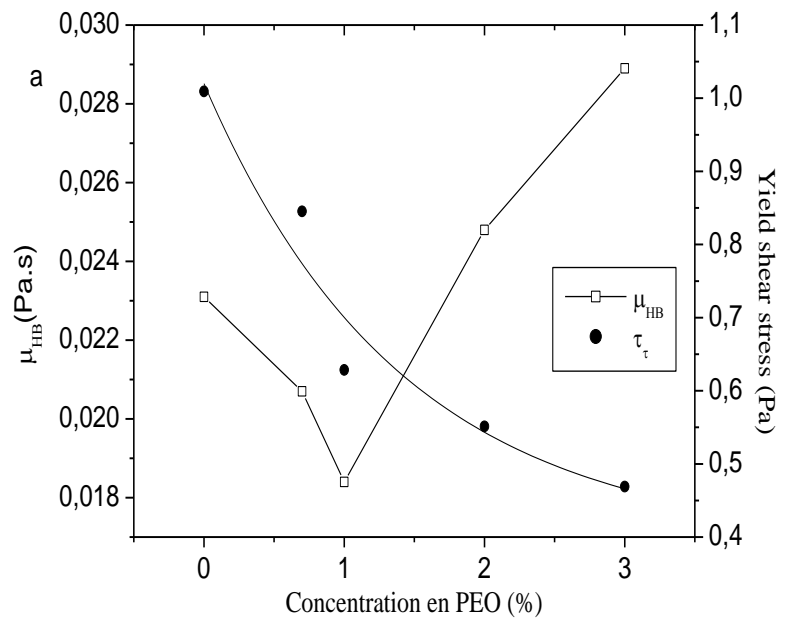

(a) particles, so reducing the interactions particle-particle and favouring the interactions particle-additive [17]. Figs. 5a-5b illustrate the parameters evolution of the Herschel-Bulkley model at the different mass concentration in PEO. A light reduction of yield stress $\tau_{\mathrm{c}}$ is observed, accompanied with a significant decline of the high shear viscosity $\left(\mu_{\mathrm{HB}}\right)$, when the quantity of polymer on the surface increases. Beyond a polymeric concentration of $1 \%$ in PEO, $\tau_{\mathrm{c}}$ is essentially constant while $\mu_{\mathrm{HB}}$ increase significantly. This last effect is due to the increase of the continuous phase of the viscosity by the presence of the polymer.

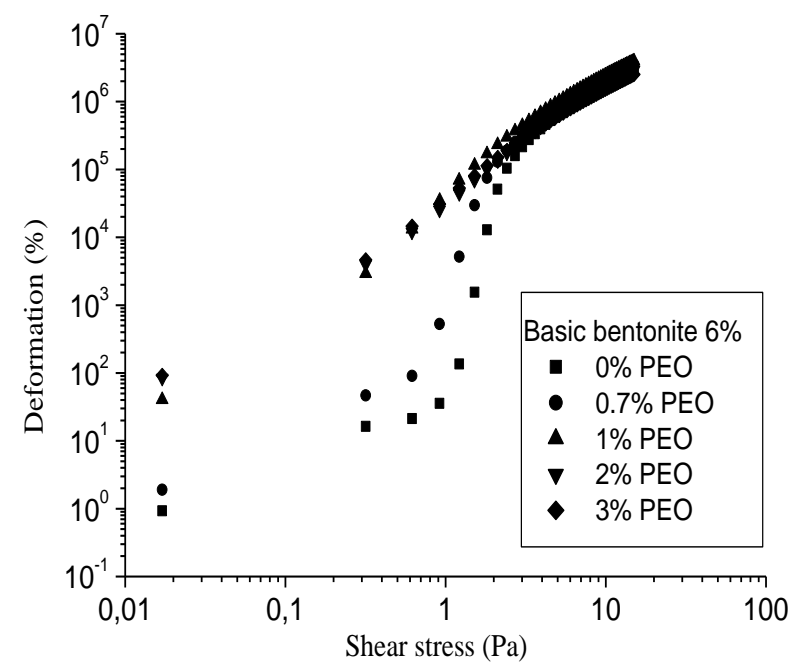

Fig. 4 Deformation shear stress curves for mixture bentonite-PEO at different concen-trations.

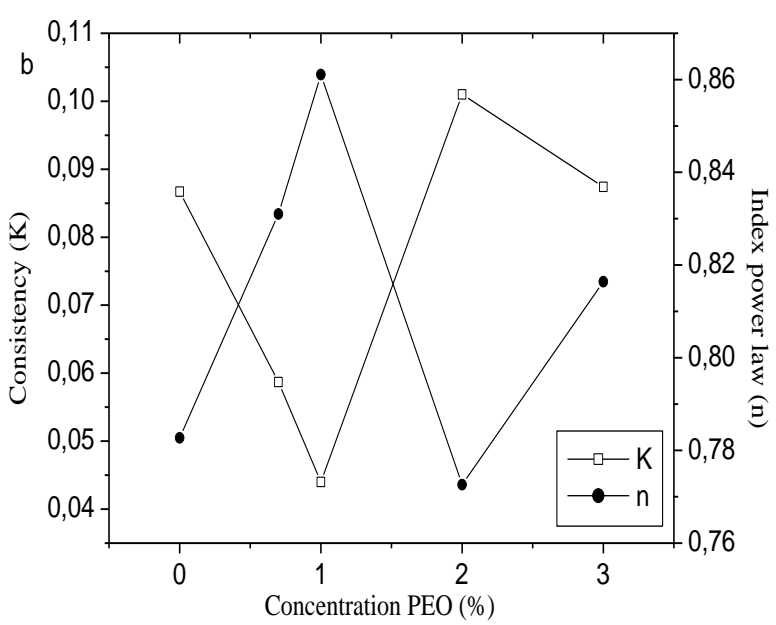

(b)

Fig. 5 Parameters of Herschel-Bulkley model as function of PEO concentrations: (a) $\mu_{\mathrm{HB}}, \tau_{\mathrm{c}}$ (b) $\mathrm{K}, \mathbf{n}$. 
Similar observations were reported by Rossi and al. $[6,18]$ on the suspensions of Na+montmorillonite $(5 \%)$ in the presence of non-ionic polymer (PEO-4000). The same observations are made on the consistency $(\mathrm{K})$ which evolves practically in the same direction as the high shear viscosity $\left(\mu_{\mathrm{HB}}\right)$ and the index of flow (n) conversely to this last one. It means, that the presence of the PEO decreases the interaction between the particles of clay (rigid) for the benefit of the interactions particles-additive (less rigid) which indeed explains the drop of $\tau_{\mathrm{c}}$.

\subsubsection{Dynamic Oscillatory Measurements}

In dynamic state, we approached the linear viscoelasticity of our mixtures suspensions by making essays of sweeping in frequency and sweeping as function time:

After four hours of rest under the geometry, so that the suspensions can reach their equilibrium state, essays of sweeping in frequency revealed that the elastic modulus $\left(\mathrm{G}^{\prime}\right)$ are superior to the loss modulus $\left(G^{\prime \prime}\right)$ for all the concentrations. It is concerned about the viscoelastic solid behaviour (Fig. 6). However, modulus $\mathrm{G}^{\prime}$ and $\mathrm{G}^{\prime}$ for mixtures always remain lower than the modulus of basic suspension ( $6 \%$ bentonite). That explains the reducing effect of the PEO on these modulus. Besides, we notice that the elastic module is independent from the frequency while the loss module increases in high and low frequency.

Besides, elastic $\left(G^{\prime}\right)$ and loss $\left(G^{\prime \prime}\right)$ modulus - time sweep was applied, to highlight the influence of the concentration in PEO on the kinetic of gel to each mixture suspension. Measures of the temporal evolution of elastic and loss modulus (at $\omega=1 \mathrm{rad} / \mathrm{s}$ ) for very low deformations were recorded for eight hours in average (Fig. 7). We notice that the most diluted system gels the least fast. These data were renormalised by the time of gel which was determined for every corresponding system to the crossing of modulus $\left(\mathrm{G}^{\prime}=\mathrm{G}^{\prime \prime}\right)$ [19]. It is interesting to notice that once re normalised, modules are little dependent on the concentration, in particular beyond the point of gel.
In this phase of the gel formation, it is thus more the kinetic of aggregation of the particles which determines the modules that the concentration.

The analysis of the Table 1 shows the evolution of the gel time $\left(t_{\text {gel }}\right)$ according to the concentration of the mixture bentonite-PEO. This time of gel always remains superior to that of the basic suspension. Consequently, we can say that the PEO slows down the kinetic of aggregation clay particles. Recently, similar studies on the laponite suspensions in the presence of PEO of low molecular weight were obtained by Mongondry [20]. Besides, it exists a critical concentration (1\%), where the gel time presents

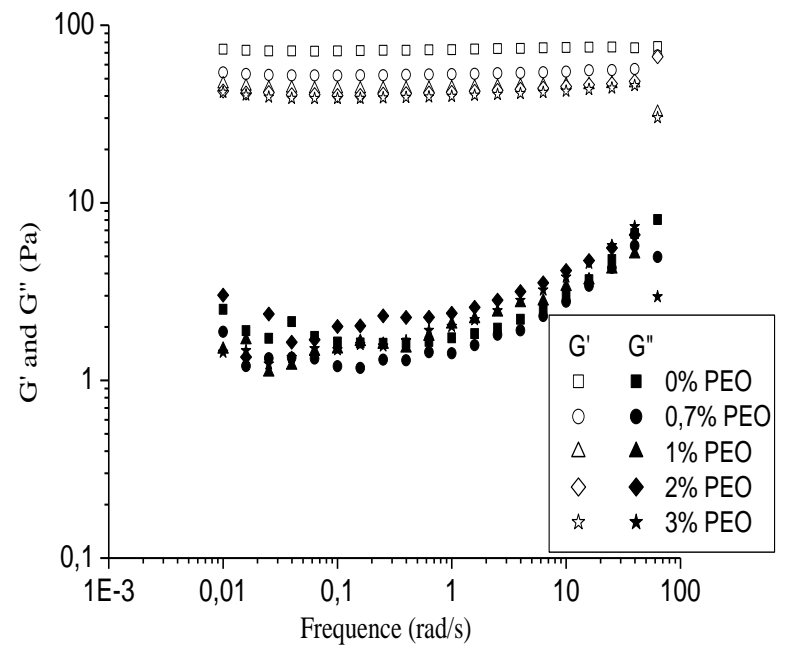

Fig. 6 Elastic and loss modulus frequency sweep as function of PEO concentration for a $6 \%$ bentonite suspension.

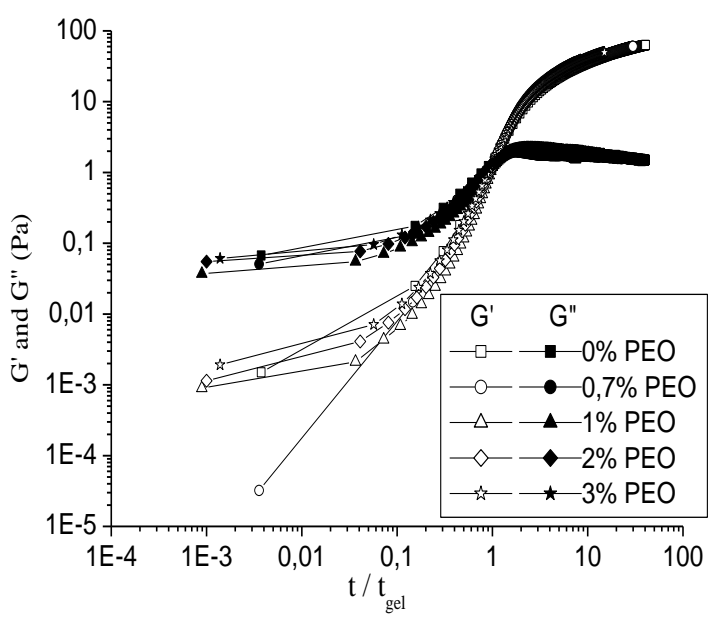

Fig. 7 Elastic and loss modulus time sweep as function of PEO concentration for a $6 \%$ bentonite suspension. 
Table 1 Gel Time for mixture bentonite-PEO.

\begin{tabular}{lllcll}
\hline System & Bent. & \multicolumn{4}{c}{ Bentonite + PEO-6000 } \\
\hline Concen. (\%) & 6 & 0,7 & 1 & 2 & 3 \\
$\mathrm{t}_{\text {gel }}(\mathrm{s})$ & 800 & 843 & 3363 & 3004 & 2163 \\
\hline
\end{tabular}

Table 2 D-spacing of the (001) peak by XRD.

\begin{tabular}{|c|c|c|c|c|c|}
\hline System & & 6 Bento & onite + & PEO-6 & 000 \\
\hline Concen. of PEO (\%) & 0 & 0,7 & 1 & 2 & 3 \\
\hline d-spacing $(001)$ peak $(\AA ̊)$ & 11,80 & 13,83 & 14,03 & 17,57 & 17,57 \\
\hline
\end{tabular}

an optimum (Max): before this critical concentration, the time gel increases and after that it decreases.

There are then two observed characteristic rheological behaviors: the first one is that corresponding to the concentrations lower than $1 \%$, where the particles of clay do not interact between them directly or by intervention of the polymer. The electrostatic repulsion being strong, the PEO is chosen then between one or several of the particles by adsorbing without being able to bridge. In that case, the PEO allows stabilizing the particles of clay. The second behavior, beyond the critical concentration where is the time of gel decreases without exceeding that of the basic suspension (800 s). We can think that there is possible appearance of the phenomenon of bridge between the particles of clay which favours system flocculation while increasing the concentration of the polymer. These chains of polymer adsorbed on the surface of the particle can interact with those which are in solution. Also, if the chain is long enough and the saturation of particles is not reached, they can adsorb on several particles at the same time (particles are now suspended by the chains of polymer as long as the saturation of particles is not reached).

The change of behavior observed on the previous figures, could be due to the microstructural relations between the polymer chains and the particles of clay. Indeed, the non-ionic polymer can coat the particles of clays or can intercalate the layers of the clay particles $[8,21]$.

\subsection{Analysis by XRD}

XRD studies could specify the nature of this rheological behavior. Indeed, this analysis by XRD of our samples bentonite-PEO mixture, dried in the ambient temperature under hood using a radiation CuK filtered by iron (source $40 \mathrm{kV}$ and $20 \mathrm{~mA}$ ), had revealed the $\mathrm{d}$-spacing of the (001) peak following (Table 2).

The mechanism envisaged possible is the following: for low concentrations in polymer $(\leq 1 \%)$, the adsorbed chains will have a flattened configuration so that the polymer does not exceed the Debye length of the particle. In that case the electrostatic repulsion will continue to impose the stability of the system. If we increase a little concentration in polymer $(>1 \%)$, the conformation flattened by chains is not possible because the number of adsorbed polymer increases. The thickness of polymers on the surface of the particles of bentonite becomes then superior to the Debye layer where the electrostatic repulsion quickly loses of their strength. So the particles bridge probability by a chain of polymer becomes much stronger as well as the surfaces are not saturated in polymer; what involves the flocculation of the suspension (the d-spacing is practically stable, while the time of gel decreases).

\section{Conclusions}

In the present paper, we investigated on one hand, the rheological behavior of the solutions of PEO which was almost Newtonian and on the other hand, the rheological behavior of the bentonite suspensions in the absence of non-ionic polymer which was practically, shear-thinning with a yield shear stress of flow at relatively high concentration $(>2 \%)$. In the presence of this additive (PEO) in the water based drilling fluids $(6 \%$ bentonite $)$, the influence was essentially discussed in terms of viscosity, yield shear stress of flow and viscoelastic modulus. It had revealed that the $\mathrm{PEO}$ which has an affinity for the bentonite particles by adsorbing, slows down their kinetics of aggregation (gel structure formation) by adopting two possible mechanisms: intercalation between the platelets of clay or then favouring the 
flocculation by forming bridges assured by the chains of polymer between the clay particles beyond critical concentration in PEO (>1\%), moreover proved by the essays of viscoelasticity and the analysis by XRD. The stability of the suspensions was improved by the polymer which gradually coated the clay particles and so involves the reduction of particle-particle interaction.

\section{References}

[1] Grim, R. E., ed. 1968. "Clay Mineralogy.” MC Graw-Hill, NY, 596.

[2] Darley, H. C. H., and Gray, G. R., ed. 1988. "Composition and Properties of Drilling and Completion Fluids." Gulf Company, Texas, 643.

[3] Then, B. K. G. 1979. "Formation and Properties of Clay-Polymer Complexes." Developments in Soil Science. Vol. (9) Elsevier Sci. Pub. Co., NY, 362.

[4] Luckham, P. F., and Rossi, S. 1999. "Colloidal and Rheological Proper-Ties of Bentonite Suspensions." Adv. Colloid Interface Sci. 82: 43-92.

[5] Shen, Z., Simon, G. P., and Cheng, Y. B. 2002. "Comparison of Solution Intercalation and Melt Interaction of Polymer-Clay Nanocomposites." Polymer. (43): 4251-60.

[6] Rossi, S., luckham, P. F., Green, N., and Cosgrove, T. 2003a. "NMR Solvent Relaxation Studies of $\mathrm{Na}+$ Montmorillonite Clay Suspensions Containing Non-ionic Polymers." Col. and Surf. A. (215): 11-24.

[7] Tombacz, E., Szekeres, M. 2004. "Colloidal Behaviour of Aqueous Montmorillonite Suspensions: The Specific Role of $\mathrm{pH}$ in the Presence of Indifferent Electrolytes." Appl. Clay Sci. (27): 75-94.

[8] Almedar, A., and Gungor, N. 2005. "The Rheological Properties and Characterization of Bentonite Dispersions in the Presence of Non-ionic Polymer PEG.” J. of Mater. Sci. (40): 171-7.

[9] Lagaly, G., and Ziesmer, S. 2006. "Sol-Gel Transition of Sodium Montmorillonite Dispersion by Cationic End-Capped Poly (Ethylene Oxide) (Surface Modification of Bentonites, IV)." Colloid Polymer Sci. (284): 947-56.

[10] Ebagninin, K. W., Benchabane, A., and Bekkour, K. 2007. "Comparative Study of Rheological Properties for the Different Molecular Weight of the Bentonite-PEO Mixture.' Presented at the 18th French Congress of Mechanic, France. (in French)
[11] Allal, A., Gareche, M., Dupin, J. C., Roby, F., and Zeraibi, N. 2009. "Modelling of Complex Shear Modulus of Bentonite Suspensions." Rhéologie, Vol. (16): 35-44. (In French)

[12] Van Olphen, H. 1964. "Internal Mutual Flocculation in Clay Suspension.', J. Col. Interf. Sci. (19): 313-22.

[13] Bekkour, K., Ern, H., and Lounis, M. 2001. “ Rheological Characterization of Emulsions $\mathrm{H} / \mathrm{E}$ and Bentonite Suspensions." Presented at the XVth French Congres Of Mechanic, Nancy, France. (In French)

[14] Guzik, J. M., Pantet, A., and Monnet, P. 1994. "Study of Rheological Characteristics for Bentonite Supensions.' Les cahiers de Rhéologie, vol. (13): 150-9. (In French)

[15] Berthier, P., and Flaud, P. 1992. "Rheological Characterization in Stationary and Non-Stationary of Drilling Fluid.' Les cahiers de Rhéologie. Vol. X (3-4): 263-70. (In French)

[16] Alderman, N. J., Gavignet, A., Guillot, D., and Maitland, G. C. 1988. "High-Temperature, High Pressure, Rheology of Water-based Muds.' Proc. 63rd ANN. Tech. Conf. Houston, 10/88, SPE 18035, 187-95.

[17] Rossi, S., luckham, P. F., and Tadros, T. 2002. "Influence of Non-ionic Polymers on the Rheological Behaviour of $\mathrm{Na}^{+}$-Montmorillonite Clay Suspensions. NonylphenolPolypropylene Oxide-polyethylene Oxide Copolymers.', Colloids Surf. A (201): 85-100.

[18] Rossi, S., luckham, P. F., and Tadros, T. 2003b. "Influence of Non-ionic Polymers on the Rheological Behaviour of $\mathrm{Na}^{+}$-Montmorillonite Clay Suspensions. Part II. Homopolymer Ethylene-oxide and Polypropylene Oxide-polyethylene Oxide ABA Copolymers." Colloids surf. A (215): 1-10.

[19] Tung, C. Y. M., and Dynes, P. J. 1982. "Relationship between Visco-elastic System.”' J. Appl. Polym. Sci. (27) 569-74.

[20] Dau, J., and Lagaly, G. 1988. "Surface Modification of Bentonites. II-Modification of Montmorillonite with Cationic Poly (Ethylene Oxide).' Croatica Chem. Acta., CCACAA71(4): 983-1004.

[21] Mongondry, P., Nicolai, T., and Tassin, F. 2004. "Influence of Pyrophosphate or Poly-Ethylene Oxide on the Aggregation and Gelation of Aqueous Laponite Dispersions.' Journal of Colloid and Interface Science (275): 191-6. 